\title{
REM KOOLHAAS: DELIRIO DE NUEVA YORK. UN MANIFIESTO \\ RETROACTIVO PARA MANHATTAN
}

\author{
Editciones Gustavo Gill. Barcelona: 2004. Ediciión original "Delirius New York", 1978
}

Rosa María Añón Abajas,

Dr. Arquitecto. Profesorar del departamento de Proyectos Arquitectónicos. Escuela Técnica Superior de Arquitectura. Universidad de Sevilla
Persona de contacto: rabajas@eus.es

e conocemos principalmente por sus obras, tan grandes, rotundas y complejas, como polémicas se ha ocupado de dejar escrita la teoría con la que ha alimentado y justificado su arquitectura. En us textos destaca "Delirio de Nueva York. Un manifiesto retroactivo para Manhattan". Publicado por primera vez en 1978, hoy cuenta con esta reseña gracias a la traducción al castellano realizada por Jorge Sainz y publicada por Gustavo Gili en 2004; por esto considero importante empezar manifestando mi gratitud a cuantos han contribuido a esa edición.

Otros escritos de Koolhaas como La ciudad genérica (2006), Espacio basura (2007), me resultaron a menos y convincentes, pero sobre todo oportunos cuando los lei. También habia visitado alguna de sus obras como la "Casa da Musica" en Oporto... La arquitectura grandilocuente me ha parecido siempre incomoda e insolidaria, pero si hay arquitectura en una obra, cuando se experimenta, convence lo suficiencomo para perdonarle los pequeños fallos, esos que si se buscan siempre se encuentran. Más allá de opinión personal que uno pueda formarse en un momento concreto e insignificante, hay que reconocer que el discurso de Koolhaas provoca al debate y a conocer la opinion de otros muchos sobre las cuestiones que plantea, las ideas que defiende y las soluciones que propone; sus obras y sus escritos son dignos de consideración.

Llegada la ocasion de este numero de PpA sobre Gran Escala, decidi proponerme como reto la lectura de este libro, contando además con el aliciente de guardar aún vivencias muy recientes de dos viajes a Nueva York, que realizados en muy distintas circunstancias y condiciones, me permitieron experiencias con tal contraste como para llegar a sentirme una habitante mas. Superponiendo a la imaginación y la ficción cinematográfica varios fragmentos encontrados comprender ese fenómeno con algo de nitidez.

Delirio de Nueva York describe la metrópoli con una técnica impresionista, mediante sueltas pinceladas superpuestas, configura imágenes cotidianas de la metrópolis en sus momentos de máxima efervescencia el motor de aquella actividad eran los eventos espectaculares, descritos por el marketing y las crónicas pe riodísticas coetáneas. La transcripción de esa literatura redactada en primera persona produce la ilusión de un viaje en el tiempo. Noticia tras noticia nos hace partícipes de la revolución que experimenta todo el que pisa Nueva York en sus años de emergencia y cómo un buen documentalista de cine, nos mentaliza para asimilar la historia que nos pretende transmitir, llena de fantástico resplandor, de excesos y también de discontinuidades y pliegues que ocultan lo feo en la sombra, haciéndolo invisible. Sombras ocultas implícitas ( Licencia admisible ya que habiendo tanto que contar y tan increíble, no queda tiempo para detenerse en

Tras una brevísima introducción sobre los orígenes del lugar y la formación de la primera colonia, pasa a exponer e identificar la tecnología derivada de las atracciones y parques sucesivamente instalados en Coney Island como el germen de la "cultura de la congestion', defendiendo la fantasía como el principal puna

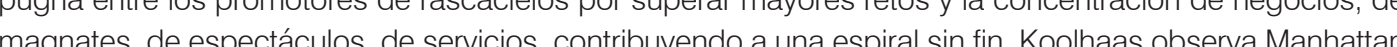
com registrados a lo largo de todo su proceso: origen, evolución, apogeo, crisis, decadencia, estabilización, permanencias... Comparte esa historia sin final conocido, compilando una densa base de datos y documentos suficientes para identificar el fenómeno que denomina "manhatanismo".

La evolución urbanística y arquitectónica de Manhattan se recrea partiendo de la descripción de un momento cultural propicio a la propagación de las ideas utópicas e higienistas, contando con los avances técnicos que los posibilitaron (principalmente el ascensor), y contando con la "genialidad" de promotores, empresarios, gestores, ingenieros y arquitectos que supieron dar viabilidad a esas especulaciones y concretarlas en un fenómeno socio-económico: el rascacielos se impone como el mejor sistema para la generación de la ciudad. Ya envuellos por esa atmóstera, el análisis de casos llega a resultarnos algo muy familiar. Esta "familiaridad" con la producción lleva a, obviando la diferencia de escala, equiparar un rascacielos con una "casa". Desde este supuesto, Manhattan con sus 2028 manzanas puede considerarse una "megaaldea".

A pantir de 1920 empiezan a destacar determinados autores vinculados a una rellexión teórica sobre rascacielos. Hugh Ferris contribuyó con sus abstractas volumetrias a asimilar el rascacielos como elemento reuestionable, sin importar su expresión. Tras la crisis de 1929 la "Asoclación del Plan Regional de Nueva York" formo una comisión para trabajar en una revisón de las directices para la construccion de la cludad", convocando a la mayoria de pensadores y teóricos de Manhattan. Harvey Wiley Corbett, profesor de la Columbia Univertsity, destacará con sus propuestas para mejorar la circulación.

Con estos fundamentos detalla casos como la manzana del hotel Waldorf-Astoria y los sucesivos proyectos que ensayaron sus posibles transiomaciones, con el Empire Stale como conclusión. un contenedor gigante que alberga mulitud de usos bajo una misma piel. Contrantamente el Downtown Alhlefic Club re presenta "el uso del edificio como máquina para generar e intensificar algunas modalidades deseables de relaciones humanas"

Estudia con especial detenimiento lo que considera el conjunto más representativo: el Rockefeller Center. Para elaborar este capítulo recurre a exponer con detalle la figura de Raymond Hood, su principal responsable y todos los proyectos para el Rockefeller Center. Dedica lo necesario a describir sus contenidos más destacables como el Radio City Music Hall o los revolucionarios murales que pinto el mejicano Diego Riveray su efímera vida en el corazón mismo del capitalismo. Mediante esta pormenorizada observación verifica los indicadores clave del sorprendente tejido de Manhattan, capaz de regenerase continuamente sobre si mismo sin acusar secuelas ni nostalgia del cluso el futuro es parte de su propia dinámica vital.

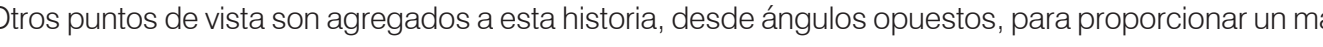
yor contraste crítico. Assi la figura del pintor Salvador Dalí, aparece como un elemento perfectamente adapado quer a Nueva York en prueba irrefulable de la idoneidad de su método "paranoico-citico" para comprender la compleja realidad de Manhaltan, es decir, ventcando conno la fantasía puede legar a oster lectual europeo de primer nivel, aparece ridiculizado gracias a los cetalles que se faclitan de su desmedida

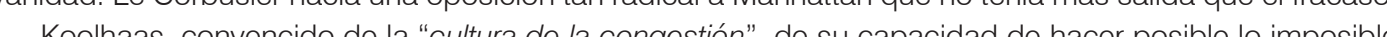

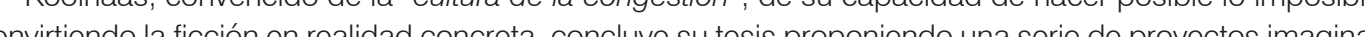
rios para Macion Son representaciones gráficas surealistas de potenciales desarollos futuros de Manhattan, aplicando la 

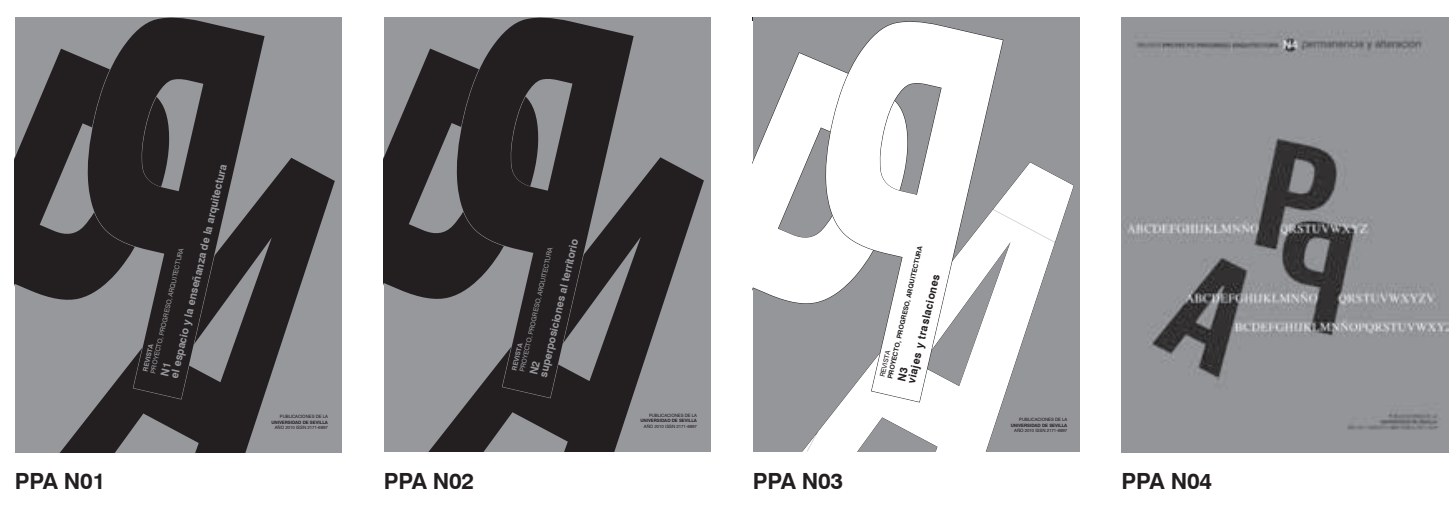

"cultura de la congestión" sin comples
clusiones de esta tesis de Koolhaas.

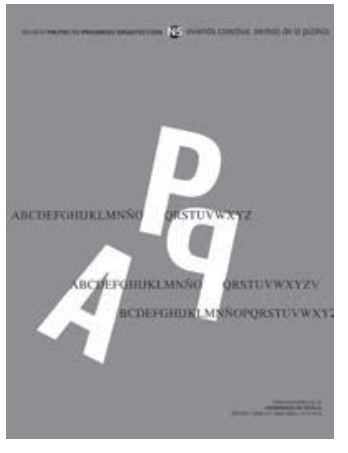

PPA No3

PPA N04

Además de una investigación cuyas conclusiones podemos no compartir, es un libro divertido que nos recordará multitud de buenas películas: "King Kong" (Merian C. Cooper y Ernest B. Schoedsack, 1933) derribando aviones encaramado al mástil del Empire State. Las relaciones extramatrimoniales disculidas en "Athletic Club", tras ser repudiado por su esposay por su amante. Imposible olvidar la increible pero real historia relatada en "El Gran Gatsby" (Baz Luhrmann, 2013), que nos muestra la opulencia de la sociedad neoyorkina dominante de los años 20 , cuestionando la integridad moral de los pobres y los ricos nuevos y viejos. Sí; finalmente creo que debo recomendar a todos esta lectura, aunque tal vez antes convenga visitar Nueva York un par de veces.

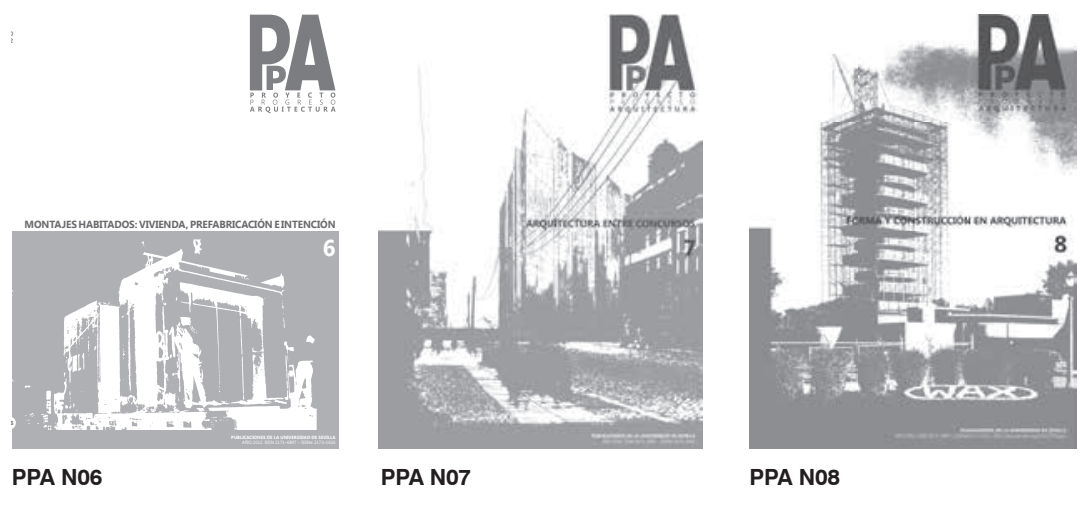

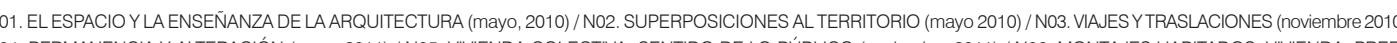

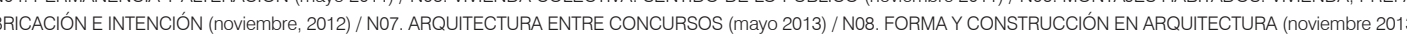

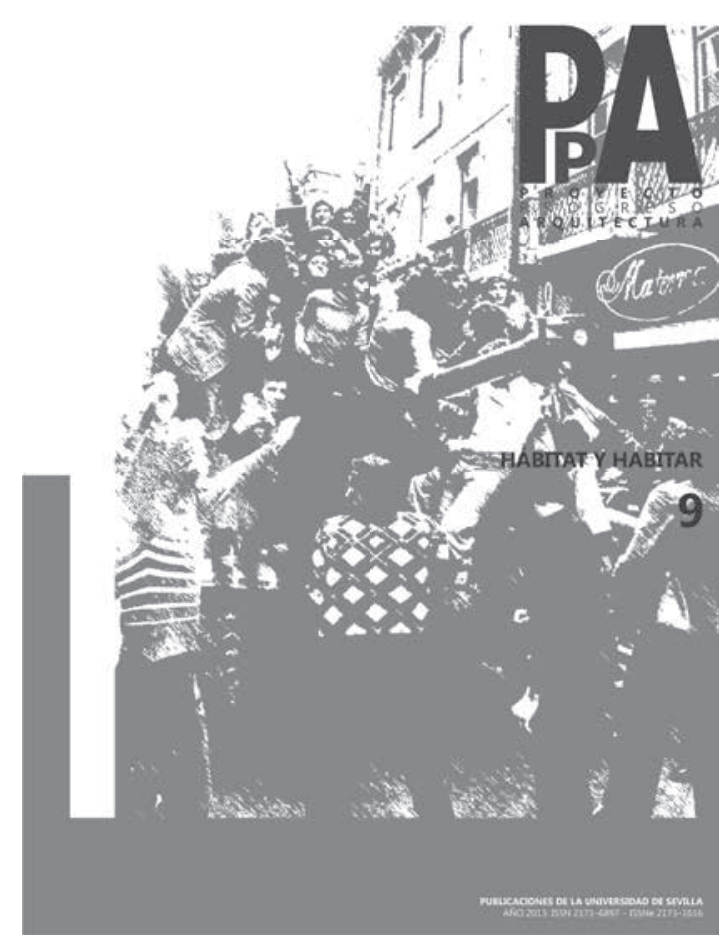

